\title{
LA IMAGEN Y EL CINE EN LA ENSEÑANZA DE LA HISTORIA ECONÓMICA
}

\author{
Image and cinema in the teaching \\ of economic history
}

Joan Miguel Tejedor Estupiñán ${ }^{1}$, Mónica Zoraya Gaitán Divantoque ${ }^{2}$

Fecha de recepción: 13 de octubre de 2016

Fecha de aceptación: 07 de noviembre de 2016

1- Nacionalidad: Colombiana. Grado: Doctor (c) en economía. Especialización: Maestría en derechos humanos. Adscripción: Universidad Católica de Colombia. Correo electrónico: jmtejedor@ucatolica.edu.co

2- Nacionalidad: Colombiana. Grado: Maestria (c) en historia. Especialización: Historia de las mujeres. Adscripción: Investigadora independiente. Correo electrónico: monicagaitan11@hotmail.com 


\section{Resumen}

Este artículo presenta el modelo de enseñanza desarrollado en las asignaturas de Historia Económica de Colombia e Historia Económica Mundial, en el programa de Economía de la Universidad Católica de Colombia, 2014 y 2015, cuyo objetivo es abordar los problemas históricos de la economía, a través de las fuentes tradicionales, complementadas con la fotografía, el cine, y demás herramientas que brindan las nuevas tecnologías de la comunicación. En la primera parte se describe el contexto de la educación en Colombia en lo que se refiere a la catedra de Historia Económica, en la segunda parte, se describe el modelo de enseñanza de la historia económica a través del cine, en la tercera parte se presenta un listado de films para complementar el proceso de enseñanza de la historia económica, en la cuarta parte se enumeran algunos recursos didácticos y fuentes de investigación que ofrece la internet, y finalmente se presentan las conclusiones.

Palabras clave: Historia económica, metodología de investigación, cine, fotografía, enseñanza y aprendizaje.

\section{Abstract}

This article presents the teaching model developed in the subjects of Economic History of Colombia and World Economic History, in the Economics program of the Catholic University of Colombia, in the years 2014 and 2015, whose objective is to address the historical problems of the economy, through traditional sources, complemented by photography, cinema, and other tools provided by new communication technologies. The first part describes the context of education in Colombia with regard to the chair of Economic History, the second part, describes the model of teaching economic history through film, the third part presents a list of films to complement the process of teaching economic history, in the fourth part illustrate some didactic resources and research sources offered by the internet, and finally the conclusions are presented.

Keywords: Economic history, methodology of research, cinema, photography, teaching and learning. 


\section{Introducción}

$\mathrm{B}$ asados en la experiencia del proceso de enseñanza aprendizaje desarrollado en las asignaturas de Historia Económica de Colombia e Historia Económica Mundial, en el programa de Economía de la Universidad Católica de Colombia, en el I y II semestre de 2014 y el I semestre de 2015, éste artículo presenta un modelo de enseñanza alternativo para implementar en las asignaturas relacionadas con la historia económica, en el cual se explica el acercamiento a los problemas históricos de la economía, a través de la consulta de fuentes primarias y secundarias tradicionales, de la imagen, del cine (objeto de este estudio), de la interacción en las aulas virtuales (entre otras TIC), complementado con el debate, la lectura y la redacción de documentos científicos (entre otras actividades), buscando promover en los estudiantes, un aprendizaje más completo, comprendiendo de manera objetiva y crítica la evolución, trasformaciones y desarrollo de la economía a nivel mundial, y nacional (identificando incluso las teorías y el pensamiento económico).

Situados en el contexto de la educación superior en Colombia y basados en una muestra de la literatura que evidencia los vínculos entre el cine, la historia y la enseñanza de la historia económica, esta propuesta busca fomentar en los docentes de historia económica el uso de herramientas alternativas y fuentes cinematográficas con el fin de adaptarse a las actuales tendencias curriculares, buscando fomentar en los estudiantes, las habilidades de lectoescritura, investigativas, argumentativas, de análisis crítico y síntesis, así como las capacidades para consultar fuentes y bases de datos (físicas y electrónicas) y manejar las Tecnologías de la Información y la Comunicación (TIC), fortaleciendo en ellos una formación integral y las cualidades de la ética profesional.

En este sentido este artículo se compone de cinco partes: en la primera parte se presenta una descripción del contexto de la educación superior en Colombia en relación al currículo de economía en las universidades colombianas, específicamente en lo que se refiere a la catedra de Historia Económica, en la segunda parte, se describe el modelo de enseñanza de la historia económica a través del cine, en la tercera parte se presenta un listado de films con los cuales se puede complementar el proceso de enseñanza de la historia económica (en este artículo nos enfocaremos en la historia económica mundial), en la cuarta parte se enumeran algunos recursos didácticos y fuentes de investigación que ofrece la internet, y finalmente se presentan las conclusiones.

\section{Contexto}

La catedra de historia económica mundial y nacional o las cátedras de historia o evolución del pensamiento económico en economía han perdido cabida dentro de los contenidos curriculares de las diferentes Facultades de Ciencias Económicas y Administrativas en Colombia, con la aplicación de los créditos académicos y la consecuente reducción del tiempo de la clase magistral y el incremento del trabajo autónomo del estudiante, se ha venido reduciendo el tiempo en los escenarios académicos para la investigación y discusión acerca de estos contenidos fundamentales para la formación integral de un profesional de las ciencias económicas. En este contexto, la implementación y el uso productivo de las tecnologías de la información y la comunicación (TIC), junto al uso de fuentes complementarias de investigación, se han convertido en una herramienta importante para impulsar tanto nuevas metodologías 
de investigación como innovadores procesos de enseñanza aprendizaje dentro y fuera del salón de clases.

En Colombia la metodología por la cual se establecen las condiciones mínimas de calidad y demás requisitos para el ofrecimiento y desarrollo de programas académicos de educación superior se ha venido implementando desde la aplicación del Decreto 808 del 25 de abril de 2002 (Ministerio de Educacion Nacional, 2002), derogado por el art. 56 del Decreto 2566 de septiembre de 2003 (Presidencia de la República de Colombia, 2003), luego remplazado por el Decreto 1295 del 20 de abril de 2010 (Ministerio de Educación Nacional, 2010) donde se aclara en el Capítulo 4 lo concerniente a los créditos académicos, como un indicador del trabajo académico, desde donde las instituciones de educación superior deben organizar las actividades académicas de manera autónoma, buscando facilitar la movilidad nacional e internacional de los estudiantes y egresados, y la flexibilidad curricular. Los créditos académicos como indicador del trabajo académico expresan todas las actividades que hacen parte del currículo que deben cumplir los estudiantes. EL MEN propone que un estudiante no debe tener más de 54 horas de trabajo semanal total (no recomendable por excesivo) que incluyen el trabajo de acompañamiento directo del docente y el trabajo independiente del estudiante, en esta relación el estudiante no debiera tener más de 18 horas semanales presenciales o de acompañamiento directo del docente, las cuales son equivalentes a los 18 créditos. Se sugiere, entonces, no incrementar el tiempo directo de trabajo con el docente, sino incrementar el tiempo de trabajo independiente del estudiante (Ministerio de Educación Nacional, 2010).

La educación (formación de capital humano) en Colombia dentro del proceso multidimensional llamado Globalización, en lo concerniente a las asignaturas relacionadas con la Historia Económica no ha permanecido ajena a los cambios. A nivel nacional las asignaturas que predominan en los nuevos Grados dentro de las Facultades de Ciencias Económicas y Administrativas, son las denominadas Historia Económica Mundial, la Historia Económica de Colombia y, luego, Historia del Pensamiento Económico e Historia de la Administración o de la Contabilidad, y mucho menos presencia de asignaturas con enfoque histórico sobre los sistemas monetarios y financieros, de la industria y del trabajo.

El estudio de Baringas y Revuelta, (2011), plantea que en estas asignaturas es necesario rediseñar la metodología de la enseñanza y el aprendizaje, enfocándose en los objetivos para los cuales se diseñaron, adaptando los contenidos a la disminución del tiempo de clase aportando a complementar la exposición del docente, facilitando el acceso al material de aprendizaje para el trabajo del estudiante, aprovechando las capacidades de las TIC como complemento de este proceso, incrementando la interactividad y fomentando el trabajo en equipo, la investigación, el hábito por la lectura, la escritura y el respeto por los derechos de autor. El estudio de Baringas y Revuelta, (2011), se enfoca en los documentales (recomendando algunos) como herramienta más concreta, didáctica y práctica para los estudiantes, la cual complementa al cine que puede ser demasiado prolongado, anacrónico y contener en ciertos casos algún grado de fantasía.

Los análisis de Barrenetxea (2006) y Aparicio, (2007), revindican una corriente de historiadores que se ha planteado analizar el cine, no sólo como un elemento didáctico para la academia, sino también como fuente para la investigación y la enseñanza de la historia, dadas las características de la imagen como una fuente de creación e inspiración poseedora de un lenguaje variado y dinámico. Percibiendo el cine, no desde una óptica en la que la imagen sustituya a la historia ni represente una fiel copia del pasado, y teniendo en cuenta que la historia es una interpretación, objetiva, pero al mismo tiempo subjetiva dadas condiciones inherentes al propio contexto político, lo cual es evidencia de la complementariedad del cine 
con la historia en el sentido que las dos reflejan una perspectiva de la sociedad.

Es así como el cine desde su naturaleza se desarrolla como dispositivo tecnológico, como dispositivo visual, sonoro y audiovisual, como dispositivo narrativo, como dispositivo socio-económico, como dispositivo espectatorial y finalmente como dispositivo estético artístico (Monterde, Masoliver y Arguimbau, 2002), permitiendo que estos dispositivos se asocien y complementen de manera exitosa en el proceso de enseñanza aprendizaje en un contexto como el que se establece por medio de los créditos académicos, en la medida en que se complementa el tiempo de trabajo tanto dependiente como independiente del estudiante, sacando provecho de las cualidades de dichos dispositivos. Es importante resaltar que muchas películas han superado incluso procesos de censura para poder traer el pasado al presente y de esta manera constituirse como verdadero cine histórico el cual se convierte en referente y símbolo de la memoria fílmica de la sociedad moderna. Desde la realización de la lectura histórica del film y del discurso histórico manejado en el mismo, podemos hacer uso de fuentes que permitirán enriquecer la comprensión de los problemas no solo históricos sino económicos (Fuentes y Peréz, 2005).

Es necesario destacar algunos estudios actuales que resaltan el trabajo documental (de temática indígena en este caso) impulsado por instituciones estatales, llegando a discutir de manera controvertida sus potencialidades como documento y como discurso histórico y político, en el cual se insertan las comunidades para discutir sobre la diferencia y complementariedad entre el performance y la realidad y así proponer acercarnos a otras realidades alternativas (Mora, 2017).

Finalmente, dentro de la literatura que describe los aportes del cine a la historia Ferro (1980), describe la importancia de la imagen y su relación con la legitimidad como arte, su capacidad transformadora de la realidad y los diferentes enfoques que se le puede dar a la historia desde la creación cinematográfica tanto desde las diferentes corrientes dominantes del pensamiento como desde la misma percepción del director. En lo relacionado específicamente con el campo de la historia cinematográfica son de bastante ilustración, en primer lugar, el trabajo de Sadoul (1987), quien hace una descripción desde el cine mudo, pasando por el cine hablado, la época contemporánea del cine, el cine en África, América Latina y Asia y las diferentes técnicas de cine como la animación entre otras, y en segundo lugar la investigación de Gubern (1969), sobre la historia del cine ubica los orígenes del cine en tiempos mucho más remotos en el mundo primitivo donde las pictografías como las de la cueva de Altamira en España, son evidencias de los orígenes del mito de la reproducción gráfica del movimiento, el cual se pudo hacer realidad gracias al cine.

\section{Modelo de enseñanza de la historia económica a través del cine}

Dado que el sistema de créditos académicos descrito anteriormente establece los tiempos y espacios deseados para desarrollar el proceso de formación de un profesional (en nuestro caso) de las ciencias económicas, por un lado la hora del trabajo dependiente, se desarrolla por lo general en el aula de clase, en auditorios o aulas virtuales con las que cuentan las instituciones en las cuales por lo general en este tiempo se desarrollan clases y exposiciones magistrales por parte del docente que orienta el curso durante el semestre; por otro lado las dos horas de trabajo autónomo son dispuestas por el estudiante para 
profundizar en las lecturas de los temas que serán discutidos en las sesiones presenciales y en el desarrollo de habilidades de investigación, en estas dos horas también se busca que los estudiantes desarrollan talleres y actividades (como reseñas y ensayos) que fomenten sus capacidades de consulta de fuentes, capacidades de lecto-escritura y demás habilidades que requiere el perfil del profesional investigador en ciencias económicas.

En la última década, la catedra de Historia Económica ha perdido tiempo de trabajo dentro del aula de clase, antes del 2003 en los currículos de economía en Colombia se enseñaban cuatro horas de esta asignatura en promedio a la semana, en la actualidad solo se ocupan dos horas por semana cada semestre al desarrollo de esta asignatura. En el caso de los programas de economía aún persisten las cátedras de Historia Económica Mundial e Historia Económica de Colombia, pero como observamos con un 50\% menos de carga horaria que hace 12 años, afectando directamente una asignatura que requiere de más tiempo para poder desarrollar todos sus contenidos, los cuales no es posible abarcar en un semestre de 16 sesiones, de 2 horas cada una, es decir en 32 horas de trabajo dependiente por semestre para un curso de historia económica, en el cual los estudiantes deben emplear 64 horas de trabajo independiente (Presidencia de la República de Colombia, 2003).

Por lo tanto, enseñar historia económica es una gran responsabilidad y esto se debe a la importancia de trasmitir de manera objetiva al profesional en ciencias económicas, el desarrollo humano desde su faceta económica y su evolución e impacto en el desarrollo social a través del tiempo, por tal motivo la enseñanza de la historia plantea diferentes retos a la hora de trasmitir una idea o un concepto, de tal forma que lo que el docente quiera enseñar sea captado de manera objetiva y no de manera abstracta. Es imposible para un docente enseñar historia económica de manera objetiva en nuestro contexto únicamente basado en la clase magistral (con sus límites de tiempo), dado que la complejidad de los temas y diversidad de sujetos y sucesos requieren de una representación gráfica que complemente las lecturas y la exposición del docente. Por esto, en los espacios de trabajo dependiente o en las horas con el docente el uso de representaciones gráficas (como la imagen y el cine) se hace indispensable, así como de otras herramientas didácticas y tecnologías de la información y la comunicación que nos brinda la sociedad en la actualidad, los cuales permiten al docente trasmitir representaciones de la realidad de una mejor manera que lo que se puede explicar oralmente.

La necesidad de aulas virtuales e inteligentes y tecnológicas es imperante en un modelo basado en el trabajo independiente del estudiante donde se busca sacar el máximo provecho también al trabajo dependiente que se realiza en la institución. En el caso de las sesiones presenciales donde se evidencia el trabajo dependiente, acompañar la clase de historia con presentaciones desarrolladas por el docente y el estudiante donde por medio de diapositivas llenas de imágenes, video, mapas, fotografía, etc., más que de puro contenido textual dentro de una clase magistral, da una idea más completa y menos abstracta de cualquier suceso histórico, social o geopolítico que se quiera trasmitir. Igualmente, para sacar el máximo provecho del tiempo independiente de trabajo autónomo del estudiante hay que tener claros los espacios que nos brindan las TIC en la actualidad para que podamos orientarlos a utilizar este tiempo de la manera más eficiente. Dentro de estos encontramos los espacios virtuales en la internet como las aulas virtuales donde se interactúa con los estudiantes fuera del salón, las cuales cuentan con el programa y los contenidos y recursos del curso por semestre, y permiten estar en constante comunicación docente-es- 
tudiante de manera on-line $e^{3}$, por otro lado, están las bases de datos y sistemas de información y resumen como fuentes de consulta científica de calidad y finalmente páginas web de contenidos documentales, históricos e interactivos.

El modelo de enseñanza que presentamos en esta sección basado en la experiencia propuesta y desarrollada en las asignaturas de Historia Económica Mundial e Historia Económica de Colombia durante tres semestres en el periodo 2014-2015, se enfocó en maximizar la calidad del proceso de aprendizaje del estudiante centrándose en las actividades de enseñanza y aprendizaje efectuadas tanto en el tiempo de trabajo dependiente, como en el independiente que debe invertir el estudiante en cada asignatura, éstas actividades se describen en la tabla 1, que además incluso en algunos casos se complementan con otras actividades didácticas como visitas a museos, lugares históricos, parques naturales, etc, de las cuales también se pueden derivar más investigaciones.

\section{Tabla 1. Tiempo y Actividades para desarrollar en las áreas de Historia Económica}

\begin{tabular}{c|l|}
$\begin{array}{c}\text { Tiempo de trabajo del } \\
\text { Estudiante }\end{array}$ & \multicolumn{1}{c}{ Actividad } \\
$\begin{array}{c}\text { Dependiente (Sesión } \\
\text { presencial) }\end{array}$ & $\begin{array}{l}\text { Introducción: en la cual se presenta y debate el syllabus a los estudiantes con los } \\
\text { objetivos, métodos, dinámicas y fuentes que se desarrollarán en el respectivo curso } \\
\text { de historia. } \\
\text { Sesiones semanales: en las cuales el docente y los estudiantes realizan presentaciones } \\
\text { sobre el tema de la semana donde se exponen las principales ideas del tema estudia- } \\
\text { do soportadas desde las diferentes fuentes bibliográficas y fílmicas. } \\
\text { Tutorías: sesiones personales de los estudiantes y grupos de trabajo para la asesoría y } \\
\text { solución de dudas con respecto al curso. }\end{array}$ \\
$\begin{array}{c}\text { Independiente (Tiempo } \\
\text { extra clase) }\end{array}$ & $\begin{array}{l}\text { Lectura de fuentes recomendadas en el syllabus. } \\
\text { Consulta de las fuentes fílmicas (películas, documentales, cortos, etc.) recomendadas } \\
\text { (las cuales son facilitadas por el docente en los pocos casos que no se encuentran en } \\
\text { internet) para apoyar la lectura de fuentes escritas. } \\
\text { Visitas a museos, lugares históricos, parques naturales, etc. } \\
\text { Preparación de exposiciones, redacción de los ensayos y sinopsis. } \\
\text { Discusión sobre las temáticas y dudas de los estudiantes por medio del aula virtual de } \\
\text { la asignatura. }\end{array}$ \\
\hline
\end{tabular}
Fuente: Elaboración de los autores.

En nuestro caso, en cursos de 25 estudiantes en promedio, el tiempo de trabajo dependiente del estudiante que corresponde a las dos horas de clase semanales para cada sesión de las asignaturas de Historia Económica Mundial e Historia Económica de Colombia, se buscaba complementar con el tiempo independiente que equivale a las cuatro horas de trabajo extra clase que debe invertir el estudiante para desarrollar las actividades de aprendizaje complementarias descritas en la tabla 1.

Con relación a las competencias o habilidades que se busca desarrollar en el estudiante, al complementar la actividad docente y los métodos tradicionales de investigación y enseñanza, con el cine, así como el uso adecuado a las TIC, lo que se busca es incentivar en los estudiantes tanto la capacidad de análisis crítico y síntesis, como la capacidad investigativa y argumentativa. Por ejemplo, junto a la activi-

3- Para esto la Universidad Católica de Colombia cuenta con MOODLE la aplicación web de tipo Ambiente Educativo Virtual, un sistema de gestión de cursos, de distribución libre (https://moodle.org/?lang=es). 
dad de ver algún film ellos entregan una sinopsis o reseña del mismo, destacando los elementos históricos, políticos y económicos que rodean la lectura y el contenido del film.

Con relación a la investigación y argumentación, lo que se busca es incentivar la capacidad de consultar y analizar fuentes y bases de datos, las cuales permiten a los estudiantes encontrar bibliografía y referencias de alta calidad científica que fundamenten su comprensión de la evolución de la economía en el contexto histórico mundial o nacional, estimulando en ellos sus habilidades de lecto-escritura, las buenas prácticas editoriales y el respeto por los derechos de autor, ya que los talleres y ensayos elaborados por los estudiantes se fundamentan en las diversas fuentes consultadas durante el curso.

Con estas actividades se pretende que los estudiantes mejoren la capacidad de reconocer, sustentar y exponer por sí mismos, los diferentes procesos históricos en la evolución de la economía mundial de una manera más objetiva y clara apoyados de las fuentes tradicionales de consulta, así como por medio de la imagen y las fuentes cinematográficas, alejándonos de percepciones subjetivas y abstractas en las cuales pueden caer los estudiantes por falta de pedagogía o elementos didácticos que complementen el aprendizaje.

Finalmente, para medir las capacidades alcanzadas por el estudiante, la evaluación tiene en cuenta tres principales aspectos, su participación en los debates en clase, la calidad de la presentación, y la calidad del ensayo.

\section{Algunas fuentes fílmicas para enseñar historia económica}

En las últimas décadas la utilización de los documentos fílmicos como fuente para el investigador y como material didáctico en la enseñanza de la historia ha adquirido gran importancia dentro de los currículos de las escuelas de historia e historia económica (Aparicio, 2007), por ello, para complementar el programa de estudios de las asignaturas de Historia Económica Mundial e Historia Económica de Colombia en la Universidad Católica de Colombia, de las tablas 2 a la 12 se presentan un listado de películas, retroalimentado en primer lugar, desde diferentes investigaciones (Monterde et al., 2002), (Fuentes y Peréz, 2005), (Baringas y Revuelta, 2011), (Benitez, 2010), y en segundo lugar por el intercambio de opiniones con docentes de diferentes facultades de ciencias humanas y sociales en universidades en toda América y Europa, esta selección sirve de complemento para la enseñanza de estas asignaturas tanto en escenarios de trabajo dependiente como independiente, siendo una propuesta alternativa para los académicos que vean en el cine una herramienta docente y una fuente para la enseñanza de la historia económica.

Como fuente documental escrita, que sin embargo se puede conseguir de manera on-line en algunos casos, algunas de las obras más utilizadas por los docentes de historia económica mundial de las universidades colombianas, se encuentran los libros de Feliu i Montfort y Sudriá, (2007), Introducción a la historia económica mundial y Cameron y Neal, (2002), Historia económica mundial. Desde el paleolítico hasta el presente, sobre los cuales se tomaron los contenidos temáticos para crear las diferentes selecciones cinematográficas presentadas en las tablas 2 a la 12, con los cuales se puede complementar de manera significativa el aprendizaje de los temas presentados para el desarrollo de la asignatura de Historia Económica Mundial en particular. Con respecto al área de Historia del Pensamiento económico dentro 
de las fuentes más consultadas se identifican los trabajos de Brue y Grant, (2009), Landreth y Colander, (2006), donde encontramos la evolución de las diferentes escuelas del pensamiento económico desde el preclásico hasta, las neo institucionalistas o también las escuelas heterodoxas modernas. Finalmente, algunas de las obras más revisadas en las áreas de historia de la teoría económica encontramos a Ekelund y Hérbert, (2006) y su libro Historia de la teoría económica y de su Método,

Con respecto al tema de las sociedades agrarias y la economía en la antigüedad (Tabla 2), encontramos películas como La guerra del fuego, de Jean-Jacques Annaud, en la cual podemos evidenciar los modos de producción y supervivencia del hombre en el periodo de transición del paleolítico al neolítico, sus principales formas de trabajo como la caza y la recolección, los orígenes de la especialización y la proto industria, e incluso se observa como sus principales conflictos se derivaban de la protección de la pareja, la manada y el territorio como se muestra en la escena donde los hombres de la cueva son atacados por otros primates más salvajes. La película el Gladiador, ilustra la vida en la época del apogeo los imperios de Grecia y Roma entre los siglos V AC y V DC, donde se creía indecorosa toda profesión material y con el fin de producir riqueza se basaron en la esclavitud. Vemos el surgimiento de clases como proletarios, militares, legisladores, en una de sus escenas más dramáticas se muestran a todas las clases sociales de la época reunidas en el anfiteatro romano donde se ven desde los esclavos hasta los emperadores bajo un sistema de gobierno donde el pan y el circo eran la base del poder de los emperadores sobre las clases populares. Películas como El nombre de la Rosa, muestran la vida de un monje católico en plena edad media cuando la inquisición, evidenciaba la expansión del poder del imperio de la iglesia desde Roma hasta las nuevas tierras descubiertas por portugueses y españoles, donde podemos evidenciar aspectos como el origen del feudalismo y la propiedad en particular.

Tabla 2. Las sociedades agrarias y la economía en la antigüedad

\begin{tabular}{|c|c|c|c|}
\hline Titulo & Año & Duración & Director \\
\hline La guerra del fuego & 1982 & $93^{\prime}$ & Jean-Jaques Annaud \\
\hline Espartaco & 1960 & $189^{\prime}$ & Stanley Kubrik \\
\hline El nombre de la Rosa & 1986 & $125^{\prime}$ & Jean-Jaques Annaud \\
\hline Gladiador & 2000 & $150^{\prime}$ & Ridley Scott \\
\hline Los últimos días de Pompeya & 1960 & $100^{\prime}$ & Mario Bonnard \\
\hline
\end{tabular}

Fuente: Elaboración de los autores.

En la película Iván el terrible, dirigida por Serguéi Eisenstein, sobre la vida del zar Iván IV de Rusia, encontramos aspectos característicos del feudalismo tardío (y los orígenes del estado Ruso) como el Zar y sus nobles (Tabla 3), así como el poder de los patriarcas de la iglesia ortodoxa pudiéndose identificar en una de sus escenas más emblemáticas como el pueblo se extiende desde la barba de el mismo Iván como representación de la diferenciación de clases y la supremacía de la aristocracia sobre el proletariado 4 . Akira Kurosawa nos muestra en Siete Samuráis, el modo de producción en la China Feudal, dónde los

4- Como hecho histórico, la tercera parte de Iván el Terrible se empezó a rodar en 1946, pero no se completó y fue desaprobada por el Gobierno soviético. El rodaje se detuvo y todo el metraje fue confiscado y la mayor parte destruida. En 1988 se desarrolló un cortometraje con los únicos fragmentos del metraje sobrevivientes. 
campesinos pagaban tributos a los emperadores y tiranos los cuales se basaban en el fruto de su trabajo, allí también encontramos los orígenes de las revoluciones proletarias contra la tiranía feudal. Para terminar con el siglo XVIII la propia Revolución Francesa, la cual se plasma en la película La Marsellesa de Jean Renoir, se muestran los orígenes de la caída de las aristocracias francesas y españolas y el origen del estado.

Tabla 3. Feudalismo tardío y capitalismo

\begin{tabular}{|c|c|c|c|}
\hline Titulo & Año & Duración & Director \\
\hline Artemisa & 1997 & $98^{\prime}$ & Agnes Merlet \\
\hline Siete samuráis & 1954 & $205^{\prime}$ & Akira Kurosawa \\
\hline Iván el terrible & 1944 & $100^{\prime}$ & Sergei M. Eisenstein \\
\hline La Marsellesa & 1938 & $128^{\prime}$ & Jean Renoir \\
\hline Ridículo & 1996 & $98^{\prime}$ & Patrice Leconte \\
\hline
\end{tabular}

Fuente: Elaboración de los autores.

En algunas de las películas que se muestran en la tabla 4, como Kamasutra de Mira Nair se puede evidenciar especialización y producción de la seda y las especias como uno de los productos característicos de la antigua India, donde desde épocas del feudalismo se fueron dibujando las primeras rutas comerciales que conectaban especialmente a Europa con Asía, África y América desde donde se pudieron enriquecer los imperios Británicos, Franceses, Portugueses y Españoles en particular por medio del modelo de conquista y colonización, donde identificamos aspectos como el origen del comercio internacional el cual se basaba especialmente en la exportación de esclavos desde África para las colonias en América y de oro y plata desde América o África para los centros en Europa, como se ve en Cabeza de Vaca, La conquista del Paraíso o en la última escena de Apocalipto, donde se escenifica el comienzo de la invasión y saqueo de Ámérica por migrantes provenientes de España y en especial el encuentro de dos culturas con modos y sistemas de producción muy distintos.

\section{Tabla 4. Expansión comercial y políticas mercantilistas}

\begin{tabular}{|c|c|c|c|}
\hline Titulo & Año & Duración & Director \\
\hline Kamasutra & 1996 & $115^{\prime}$ & Mira Nair \\
\hline Hero & 2002 & $99^{\prime}$ & Zhang Yimou \\
\hline Cabeza de vaca & 1991 & $112^{\prime}$ & Nicolás Echevarría \\
\hline Apocalipto & 2006 & $136^{\prime}$ & Mel Gibson \\
\hline La conquista del paraíso & 1992 & $155^{\prime}$ & Ridley Scott \\
\hline
\end{tabular}

Fuente: Elaboración de los autores.

Para conocer los orígenes del capitalismo impulsado desde la revolución industrial del siglo XVIII, de 
las clases sociales (burgueses y proletarios), la división del trabajo, la plusvalía, el incremento de productividad generado del desarrollo tecnológico, la enajenación del trabajo y la alienación del trabajador y en concreto la consolidación del modo de producción capitalista, podemos lograr una clara descripción si observamos (entre otras, ver tabla 5) la película Daens, de Stijn Coninx, y la Tierra de la Gran promesa, de Andrzej Wajda dónde claramente se observa la explotación laboral, el trabajo infantil y femenino, entre otros problemas de la revolución industrial.

Tabla 5. Revolución industrial e industrialización

\begin{tabular}{|c|c|c|c|}
\hline Titulo & Año & Duración & Director \\
\hline Daens & 1993 & $138^{\prime}$ & Stijn Coninx \\
\hline Germinal & 1993 & $158^{\prime}$ & Claude Berri \\
\hline La tierra de la gran promesa & 1975 & $168^{\prime}$ & Andrzej Wajda \\
\hline Río Rojo & 1948 & $133^{\prime}$ & Howard Hawks \\
\hline La nuit de Varennes & 1982 & $131^{\prime}$ & Ettore Scola \\
\hline El Gatopardo & 1963 & $205^{\prime}$ & Luchino Visconti \\
\hline
\end{tabular}

Fuente: Elaboración de los autores.

La lucha de clases y el movimiento obrero que surgió de la explotación de los campesinos en Italia cuando nacía el fascismo, podemos observarla en Novecento de Bertolucci (Tabla 6.), donde la ausencia de justicia para los oprimidos trabajadores muestra un proceso de transformación del campo italiano.

Tabla 6. Sistemas agrarios y consolidación de la propiedad

\begin{tabular}{|c|c|c|c|}
\hline Titulo & Año & Duración & Director \\
\hline Novecento & 1976 & $162^{\prime}$ & Bernardo Bertolucci \\
\hline Shane (Raíces profundas) & 1953 & $118^{\prime}$ & George Stevens \\
\hline Cristo se paró en Éboli & 1979 & $150^{\prime}$ & Franceso Rosi \\
\hline Tess & 1979 & $172^{\prime}$ & Roman Polanski \\
\hline
\end{tabular}

Fuente: Elaboración de los autores.

En Tiempos Modernos de Charles Chaplin (tabla 7) podemos encontrar las características de la segunda revolución tecnológica caracterizada por la consolidación del sistema de producción capitalista, el incremento de la productividad gracias a la división del trabajo y el desarrollo de la tecnología, la consolidación de las clases sociales en especial la burguesa y el proletariado (en especial el proletariado fabríl). 
Tabla 7. Segunda revolución tecnológica

\begin{tabular}{|c|c|c|c|}
\hline Titulo & Año & Duración & Director \\
\hline Tiempos modernos & 1936 & $8^{\prime}$ & Charles Chaplin \\
\hline Good morning Babilonia & 1986 & $115^{\prime}$ & Paolo y Vittorio Taviani \\
\hline
\end{tabular}

Fuente: Elaboración de los autores.

Para entender los estragos de la gran depresión Las uvas de la ira (tabla 8), de John Ford, podemos recordar la escena cuando John regresa a casa y la encuentra vacía, los arrendatarios expulsados por los tractores de los propietarios de las tierras, se puede observar como la productividad derivada de desarrollo tecnológico, los intereses de los banqueros y las grandes compañías, aplastan a los campesinos, se muestra el desplazamiento de los campesinos del campo a la ciudad y la consolidación de los centros urbanos para la concentración de un ejército de mano de obra barata.

Tabla 8. La gran Depresión de los años 30

\begin{tabular}{|c|c|c|c|}
\hline Titulo & Año & Duración & Director \\
\hline Las uvas de la ira & 1940 & $129^{\prime}$ & John Ford \\
\hline Qué bello es vivir & 1946 & $130^{\prime}$ & Frank Capra \\
\hline
\end{tabular}

Fuente: Elaboración de los autores.

Para entender las relaciones entre el Capitalismo y el Socialismo en Alemania después de la segunda guerra mundial y observar también la expansión del capital trasnacional, entre otras películas, podemos recurrir a Uno, dos, tres (tabla 9), de Billi Willder, donde desde la perspectiva de un empresario de una compañía multinacional Norte Americana de gaseosas que quiere expandirse hacia la Unión de Repúblicas Soviéticas Sociales, se muestran los orígenes del Capitalismo y la guerra fría. Así mismo, se puede tomar como fuente, la película Good bye Lennin, de Wolfgang Becker, quien, desde una tragicomedia, muestra la transición de Alemania del Socialismo al Comunismo luego de la caída del muro de Berlín en 1989 y la unificación de la Alemania Socialista del Este con la Alemania Capitalista de Oeste.

\section{Tabla 9. Capitalismo y Socialismo}

\begin{tabular}{|c|c|c|c|}
\hline Titulo & Año & Duración & Director \\
\hline Uno, dos, tres & 1961 & $108^{\prime}$ & Billy Wilder \\
\hline Ninotchka & 1939 & $110^{\prime}$ & Ernst Lubitsch \\
\hline El hombre de mármol & 1977 & $164^{\prime}$ & Andrejz Wajda \\
\hline El hombre de hierro & 1981 & $152^{\prime}$ & Andrejz Wajda \\
\hline Octubre & 1927 & $100^{\prime}$ & S. M. Eisenstein \\
\hline Good Bye Lenin! & 2003 & $118^{\prime}$ & Wolfgang Becker \\
\hline
\end{tabular}

Fuente: Elaboración de los autores. 
Desde la perspectiva de Edmund un niño de 12 años, el protagonista de Alemania año cero, de Roberto Rossellini, podemos ver el impacto de la segunda guerra mundial e igualmente contextualizar el surgimiento de los estados nacionales como nuevo orden mundial liderado desde Naciones Unidas, y aquellas instituciones que surgieron para la reconstrucción física y económica de las naciones devastadas por el coronamiento bélico mundial como el Fondo Monetario Internacional y el Banco Mundial. Entre otros films (Tabla 10), desde la perspectiva de Charles Chaplin, El gran dictador, es una película que a modo de parodia hace una fuerte crítica al sistema fascista imperante durante la primera guerra mundial caracterizado por la discriminación hacia los judíos.

\section{Tabla 10. Guerras mundiales y reconstrucción de la postguerra mundial}

\begin{tabular}{|c|c|c|c|}
\hline Titulo & Año & Duración & Director \\
\hline Patrulla infernal & 1958 & $88^{\prime}$ & Stanley Kubrik \\
\hline Cabaret & 1972 & $123^{\prime}$ & Bob Fosse \\
\hline Alemania año cero & 1947 & $72^{\prime}$ & Roberto Rossellini \\
\hline Ladrón de bicicletas & 1946 & $93^{\prime}$ & Vittorio de Sica \\
\hline Rocco y sus hermanos & 1960 & $170^{\prime}$ & Luchino Visconti \\
\hline El gran dictador. & 1940 & $128^{\prime}$ & Charles Chaplin \\
\hline
\end{tabular}

Fuente: Elaboración de los autores.

Los procesos de Colonialismo y en especial de descolonización se pueden analizar observando entre otras, películas como Ghandhi, de Richard Attenborough, donde se muestra el proceso de independencia de la India que a mediados del siglo XX estaba bajo el poder de Gran Bretaña. En la Batalla de Argel, de Gillo Pontecorvo, a finales de 1950 observamos el proceso de revolución argelino que les llevaría a independizarse de Francia. En el El último emperador, Bertolluci muestra la historia de Puyi el último emperador de la china que reinó en la ciudad prohibida, quien fuera influenciado por el capitalismo y luego llevado a Manchuria como marioneta de los japoneses, fue encarcelado luego por la revolución comunista y finalmente terminó sus días como un jardinero, presenciando la transición al comunismo liderado por Mao Tze Tung y su llamada Revolución Cultural.

Tabla 11. Colonialismo y descolonización

\begin{tabular}{|c|c|c|c|}
\hline Titulo & Año & Duración & Director \\
\hline La Misión & 1986 & $125^{\prime}$ & Ronald Joffe \\
\hline 55 días en Pekín & 1953 & $154^{\prime}$ & Nicholas Ray \\
\hline Memorias de África & 1985 & $160^{\prime}$ & Sidney Pollack \\
\hline Lawrence de Arabia & 1962 & $222^{\prime}$ & David Lean \\
\hline El jardinero fiel & 2005 & $128^{\prime}$ & Fernando Mereilles \\
\hline Gandhi & 1982 & $188^{\prime}$ & Richard Attenborough \\
\hline El último Emperador & 1987 & $160^{\prime}$ & Bernardo Bertollucci \\
\hline La batalla de Argel & 1965 & $120^{\prime}$ & Gillo Pontecorvo \\
\hline
\end{tabular}




\begin{tabular}{|c|c|c|c|}
\hline Titulo & Año & Duración & Director \\
\hline Domingo sangriento & 2002 & $110^{\prime}$ & Paul Gren Grass \\
\hline Memorias del subdesarrollo & 1968 & $97^{\prime}$ & Tomás Gutiérrez Alea \\
\hline
\end{tabular}

Fuente: Elaboración de los autores.

Para analizar el impacto de la especulación en la bolsa de valores y el rol de las instituciones financieras en los momentos de crisis, Wall Street, de Oliver Stone y La locura del dólar, de Frank Capra, allí se muestran las relaciones entre banqueros y empresarios y la influencia de "especulación" en la estabilidad financiera de las empresas. Para contextualizar a los estudiantes sobre la economía del petróleo podemos recurrir a Syriana, de Stephen Ghagan.

Tabla 12. Mercados Financieros en el siglo XX

\begin{tabular}{|c|c|c|c|}
\hline Titulo & Año & Duración & Director \\
\hline La locura del dólar & 1932 & $75^{\prime}$ & Frank Capra \\
\hline Wall Street & 1987 & $120^{\prime}$ & Oliver Stone \\
\hline Syriana & 2005 & $125^{\prime}$ & Stephen Ghagan \\
\hline El club de la pelea & 1999 & $151^{\prime}$ & David Fincher \\
\hline
\end{tabular}

Fuente: Elaboración de los autores.

\section{Otros recursos}

En la actualidad las TIC nos ofrecen una gran variedad de recursos didácticos que sirven de apoyo para el docente, en este sistema basado en el trabajo autónomo e independiente del estudiante y cuyo objetivo es formar profesionales integrales con cualidades investigativas. Dentro de estos recursos encontramos sitios web, bases de datos y sistemas de información y resumen que filtran la información de mejor calidad dentro del mar de información que es el internet. A continuación, se mencionan algunas de las más importantes y útiles para la enseñanza de la historia económica.

\subsection{Mapas}

Un elemento indispensable en la enseñanza de la historia es la geografía, la cartografía y lo que hoy se llama el análisis geopolítico, por ello el uso de mapas se hace indispensable, dentro de las herramientas relacionadas con mapas encontramos páginas en internet como Google Earth, mapas satelitales de todos los continentes en mapamundial.co (Mapamundi, 2014), un atlas mundial interactivo (Mapquest, 2006), también encontramos la Fundación OpenStreetMap quienes desarrollan cartografía de licencia abierta (Fundación OpenStreetMap, 2010), igualmente podemos ver en Global Administrative Areas un proyecto que busca mapear la división administrativa del planeta en (Hijmans, 2009), y finalmente herramientas que permiten incluso ver mapas que monitorean el clima (Climate Research Group, 2014). 


\subsection{Sires y BBCS}

En la actualidad los investigadores y docentes contamos en internet con Sistemas de indexación y resumen y bases de datos bibliográficas las cuales contienen resultados de investigaciones de alta calidad reconocidas por pares e instituciones de investigación y de educación superior a nivel mundial del más alto reconocimiento. Estos SIRes o BBCS, son conformadas por comités editoriales de alta calidad donde garantizan el cumplimiento de los criterios mínimos de calidad editorial y científica y se filtra la mejor información científica en el internet, algunas son de acceso abierto y otras cobran por suscripción, consolidándose como fuentes primordiales para los estudiantes e investigadores en la actualidad, dentro de estos encontramos los siguientes, cuya característica principal es el acceso abierto.

El Índice Bibliográfico Nacional Publindex es un sistema colombiano para la clasificación, actualización, escalafonamiento y certificación de las publicaciones científicas y tecnológicas. Es regido por COLCIENCIAS y el ICFES en Colombia (Publindex-Colciencias, 2002).

EconLit es la Base de datos Bibliográfica electrónica de la American Economic Association, en más de 120 años ha recopilado e indizado la literatura de la economía de todo el mundo. Compila gran variedad de documentos en un formato de fácil búsqueda. EconLit es un índice completo de artículos de revistas, libros, reseñas de libros, artículos, documentos colectivos de trabajo, y tesis de pregrado y posgrado (American Economic Association, 2013).

RePEc (Research Papers in Economics) es un esfuerzo de colaboración de cientos de voluntarios en 75 países para mejorar la difusión de la investigación en economía y ciencias afines. El corazón del proyecto es una base de datos bibliográficos descentralizados de documentos de trabajo, artículos de revistas, libros, capítulos de libros y componentes de software, todos mantenidos por voluntarios (IDEAS, 2000).

SciELO Colombia es una biblioteca electrónica que cubre una colección selecta de revistas científicas colombianas de todas las áreas del conocimiento. SciELO Colombia cuenta con un Comité Consultivo Nacional, conformado por el Instituto Colombiano para el Desarrollo de la Ciencia y la Tecnología Francisco José de Caldas Colciencias, la Organización Panamericana de la Salud-Representación Colombia, la Universidad Nacional de Colombia y representantes de los Editores (SciELO Colombia, 2002).

Redalyc.org es una iniciativa de acceso abierto a la producción científica del mundo en revistas iberoamericanas, que contempla todas las áreas del conocimiento. Ofrece una hemeroteca en línea que permite leer, descargar y compartir artículos científicos a texto completo de forma gratuita, en apoyo a las labores académicas tanto de investigadores como de estudiantes. Además, genera indicadores que permitan conocer cuantitativa y cualitativamente la forma en la que se hace ciencia en Iberoamérica (RedALyC, 2002).

CLASE es una base de datos bibliográfica creada en 1975 en la Universidad Nacional Autónoma de México (UNAM). Ofrece alrededor de 330 mil registros bibliográficos de artículos, ensayos, reseñas de libro, revisiones bibliográficas, notas breves, editoriales, biografías, entrevistas, estadísticas y otros documentos publicados en cerca de 1500 revistas de América Latina y el Caribe, especializadas en ciencias sociales y humanidades (Dirección General de Bibliotecas, 2012).

DOAJ (Directory of Open Acces Journals) es un directorio de revistas científicas on line que provee acceso abierto de calidad a revistas evaluadas por pares académicos. El objetivo de DOAJ es incrementar la visibilidad y fácil uso de revistas académicas y científicas incluyendo la promoción e impacto. El objetivo de 
DOAJ es crear un sistema de calidad y control que garantice el contenido de calidad a revistas de acceso abierto en todo el mundo (DOAJ, 2008).

Dialnet es una base bibliográfica que publica la producción científica hispana. Inició su funcionamiento en el año 2001, especializada en ciencias humanas y sociales. Su base de datos, de acceso libre, fue creada por la Universidad de La Rioja (España) (Dialnet, 2001).

La antigua Plataforma Open Access de Revistas Científicas Electrónicas Españolas y Latinoamericanas e-Revistas ahora llamada REDIB (Red Iberoamericana de Innovación y Conocimiento Científico), es un proyecto impulsado por el Consejo Superior de Investigaciones Científicas (CSIC) con el fin de contribuir a la difusión y visibilidad de las revistas científicas publicadas en América Latina, Caribe, España y Portugal (Agencia Estatal Consejo Superior de Investigaciones Científicas-Universia, 2016).

EconBiz es un portal de búsqueda para economistas, el portal inicio en 2002 como la Librería Virtual para el Estudio de los negocios y las ciencias económicas. EconBiz fue fundada por la German Research Foundation (DFG) y actualmente es impulsada por la German National Library of Economics (ZBW) con el apoyo del comité asesor de EconBiz y los pares colaboradores. El propósito principal del portal es bridar a los investigadores y profesores de economía un punto de entrada a información específica en las diferentes áreas de las ciencias económicas en texto completo (Leibniz Information Centre for Economics, 2010).

Finalmente encontramos dentro de las BBCS que cobran por suscripción a ISI Web of Science (Thomson Reuters, 2013), Scopus (Elsevier, 2002), Ebsco (Ebsco, 2010) y Proquest (ProQuest, 2010), las cuales cuentan con miles de papers, tesis, artículos y revistas con documentos para descargar en texto completo en varios idiomas, pero en especial en inglés. Otras herramientas fundamentales desarrolladas para facilitar el trabajo de los académicos e investigadores son los administradores de citas dentro de los cuales encontramos, EndNote, Mendeley, Publish or Perish y Refworks (los cuales se pueden adquirir por internet), entre otros.

\subsection{Archivos Digitales}

Encontramos el archivo de las Naciones Unidas (Naciones Unidas, 2001), y la Biblioteca Digital de la Unesco (UNESCO, 2000), entre muchos otros archivos con los que cuentan las universidades e instituciones en todo el mundo, a los cuales se puede acceder desde internet.

\section{Conclusión}

En Colombia en el actual contexto de la educación superior medida en términos de créditos académicos, el área de Historia Económica en las Facultades de Ciencias Económicas y Administrativas de las Universidades de Colombia se ha visto afectada en términos de una disminución del tiempo dedicado a esta importante área, lo cual ha llevado a que los docentes desarrollemos modelos de enseñanza apoyados en diferentes materiales, recursos didácticos (como el cine) y en las TIC, para hacer más eficiente, efectivo y de mayor calidad el proceso de aprendizaje de la historia económica en el tiempo de trabajo dependiente e independiente que un estudiante de economía debe invertir a estas asignaturas en cada semestre. 
En la actualidad el cine, la imagen y el uso de las TIC, como referentes y fuentes de investigación, permiten que los estudiantes tengan acceso a documentos de alta calidad científica que describen la evolución de la historia mundial, los cuales se complementan para mejorar de manera significativa el proceso de formación integral de los profesionales de las ciencias económicas. Por tal motivo el avance, adecuación y manejo de espacios inteligentes y aulas virtuales que complementen las aulas tradicionales de pupitres y tableros y las fuentes tradicionales de investigación, resultan indispensables para aprovechar el tiempo de trabajo independiente de los estudiantes, de tal manera que se pueda fortalecer el proceso de enseñanza aprendizaje de la historia económica y ofrecer una educación de alta calidad.

Actualmente existe una gran cantidad de producción cinematográfica que es utilizada en centros de investigación y universidades como herramienta para la enseñanza de la historia económica, la cual además de convertirse en una fuente importante para la investigación, sirve como instrumento audio visual que complementa las fuentes bibliográficas y de esta manera ayuda a desarrollar con los estudiantes un abordaje objetivo de los problemas de la evolución de la economía mundial, desarrollando en ellos habilidades de argumentación, escritura, e investigación, en un contexto de educación de alta calidad.

\section{Referencias}

Agencia Estatal Consejo Superior de Investigaciones Científicas-Universia. 2016. Red Iberoamericana de Innovación y Conocimiento Científico. https://www.redib.org/ (10 de mayo, 2016).

American Economic Association. 2013. Econlit. https://www.aeaweb.org/econlit/ (11 de septiembre, 2015).

Aparicio, Eliseo Valle. 2007. Cine e historia: sobre la utilización de los documentos soporte video en la enseñanza de la historia. En Actas del I Congreso INternacional de Lengua, Literatura y Cultura Española: La Didáctica de la enseñanza para extrangeros. Valencia. DOI: https://doi.org/10.1016/j.tet.2006.09.105. Baringas, Miguel y Julio Revuelta. 2011. La historia económica contada en imágenes : una guía práctica. http://ocw.unican.es/ciencias-sociales-y-juridicas/historia-economica-mundial/historia-economicamundial-2010/otros-recursos-1/OR-II.5.pdf.

Barrenetxea, Igor. 2006. Pensar la historia desde el cine. Entelequia: revista interdisciplinar, 1(1): 99-108. Benitez, Mauro Hernandez. 2010. Cine para enseñar historia económica: propuesta de títulos. http:// portal.uned.es/portal/page?_pageid=93,793496\&_dad=portal (23 de marzo, 2016).

Brue, Stanley y Randy Grant. 2009. Historia del pensamiento económico. México D.F.: Cengage.

Cameron, Rondo y Larry Neal. 2002. Historia económica mundial. Desde el paleolítico hasta el presente. Oxford: Alianza Editorial.

Climate Research Group. 2014. Global Climate. http://www.globalclimatemonitor.org/ (13 de mayo, 2015).

Dialnet, Fundación. 2001. Dialnet. https://dialnet.unirioja.es/ (10 de mayo, 2015).

Dirección General de Bibliotecas, UNAM. 2012. Citas Latinoamericanas en Ciencias Sociales y Humanidades. UNAM. http://clase.unam.mx/F?func=find-b-0\&local_base=cla01 (15 de diciembre, 2015).

DOAJ. 2008. Directory of Open Access Journals. https://doaj.org/ (10 de mayo, 2015).

Ebsco. 2010. EconLit with Full Text | American Economic Association Database | EBSCO. Ebsco Indus- 
tries. http://www.ebscohost.com/academic/econlit-with-full-text (1 de junio, 2015).

Ekelund, Robert B y Robert F Hérbert. 2006. Historia de la teoría económica y de su Método. México D.F.: McGrawHill.

Elsevier. 2002. Scopus. Relx Group. https://www.scopus.com/ (11 de septiembre, 2015).

Feliu i Montfort, Gaspar y Carles Sudriá. 2007. Introducción a la historia económica mundial. Valencia: Universidat de Valencia.

Ferro, Marc. 1980. El Cine una visión de la historia. Madrid: Ediciones Akal.

Fuentes, María y María Peréz. 2005. La memoria filmada: América Latina a través de su cine. El cine como fuente para la historia y recurso pedagógico en la enseñanza de la historia de América. Procesos Históricos, 4 (8): 1-15.

Fundación OpenStreetMap. 2010. OpenStreetMap. https://www.openstreetmap.org/ (13 de mayo, 2015). Gubern, Román. 1969. Historia del cine. Madrid: Anagrama Compendium

Hijmans, Robert. 2009. Global Administrative Areas - Boundaries without limits. http://gadm.org/ (13 de mayo, 2015).

IDEAS. 2000. Research Papers in Economics. Research Division Federal Reserve Bank of St. Louis. http:// ideas.repec.org/i/a.html (1 de enero, 2015).

Landreth, Harry y David C. Colander. 2006. Historia del pensamiento económico. Madrid: McGrawHill.

Leibniz Information Centre for Economics. 2010. EconBiz. https://www.econbiz.de/ (15 de diciembre, 2015).

Mapamundi. 2014. Mapa mundial. http://mapamundial.co/ (13 de mayo, 2015).

Mapquest. 2006. HRW Atlas Mundial. https:/go.hrw.com/atlas/span_htm/world.htm (13 de mayo, 2015).

Ministerio de Educación Nacional. 2002. Decreto 0808 de Abril 25 de 2002. Colombia: Ministerio de Educación Nacional.

Ministerio de Educación Nacional. 2010. Decreto 1295 de 2010. Ministerio de Educación Nacional. Colombia: Ministerio de Educación Nacional.

Monterde, José, Marta Selva y Solá Arguimbau. 2002. La representación cinematográfica de la historia. Madrid: Ediciones AKAL.

Mora, Julimar del Carmen. 2017. El cine documental " radical ” y la construcción de historias subalternas. Reflexiones en torno al film "Sabino Vive, las últimas fronteras". Nóesis. Revista de Ciencias Sociales y Humanidades, 26 (51): 58-83. DOI: https://doi.org/http://dx.doi.org/10.20983/noesis.2017.1.4.

Naciones Unidas. 2001. Internet Archive. UNESCO. https://archive.org/ (10 de mayo, 2015).

Presidencia de la República de Colombia. 2003. Decreto 2566 de Septiembre 10 de 2003. Colombia: Ministerio de Educación Nacional.

ProQuest. 2010. ProQuest. http://www.proquest.com/products-services/title-lists/tl-menu.html (1 de junio, 2015).

Publindex-Colciencias. 2002. Publindex. http://publindex.colciencias.gov.co:8084/publindex/ (1 de junio, 2015).

RedALyC. 2002. Red de Revistas Científicas de América Latina y el Caribe, España. Universidad Autónoma del Estado de México. México D.F. http://www.redalyc.org/info.oa?page=/acerca-de/faqredalyc. html\#tab11 (15 de diciembre, 2015). 
- Revista de Ciencias Sociales y Humanidades. ISSN-P: 0188-9834 ISSN-E: 2395-8669.

Sadoul, Georges. 1987. Historia del cine mundial: desde los orígenes. México D.F.: Siglo XXI.

SciELO Colombia. 2002. Scientific Electronic Library Online-SciELO. SciELO - Scientific Electronic Library Online. http://www.scielo.co/ (15 de diciembre, 2015).

Thomson Reuters. 2013. Web of Science ${ }^{\bullet}$. http://ipscience.thomsonreuters.com/product/web-of-science/ (15 de diciembre, 2015).

UNESCO. 2000. Biblioteca Digital Mundial. http://www.wdl.org/es/ (15 de diciembre, 2015). 